\title{
Factors influencing the decision to pursue emergency medicine as a career among medical students in Singapore
}

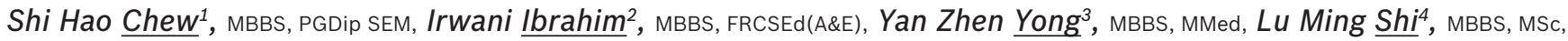
Qi Shi Zheng 4 , MBBS, MPhil, Dujeepa D Samarasekera ${ }^{5}$, MBBS, FAMEE, Shirley Beng Suat Ooi ${ }^{2}$, MBBS, FRCSEd(A\&E)

INTRODUCTION The introduction of the residency programme in Singapore allows medical students to apply for residency in their graduating year. Our study aimed to determine the interest levels and motivating factors for pursuing emergency medicine (EM) as a career among medical students in Singapore.

METHODS A self-administered questionnaire was distributed to Year 1-5 medical students in 2012. Participants indicated their interest in pursuing EM as a career and the degree to which a series of variables influenced their choices. Influencing factors were analysed using multinomial logistic regression.

RESULTS A total of 800 completed questionnaires were collected. $21.0 \%$ of the participants expressed interest in pursuing EM. Perceived personality fit and having done an elective in EM were strongly positive influencing factors. Junior medical students were more likely to cite the wide diversity of medical conditions and the lack of a long-term doctor-patient relationship to be negative factors, while senior medical students were more likely to cite personality fit and perceived prestige of EM as negative factors.

CONCLUSION Careful selection of EM applicants is important to the future development of EM in Singapore. Our study showed that personality fit might be the most important influencing factor in choosing EM as a career. Therefore, greater effort should be made to help medical students explore their interest in and suitability for a particular specialty. These include giving medical students earlier exposure to EM, encouraging participation in student interest groups and using appropriate personality tests for career guidance.

Keywords: emergency medicine, medical internship and residency, students, surveys and questionnaires

\section{INTRODUCTION}

The emergency medicine (EM) residency programme was introduced in Singapore in 2010 as part of a nationwide effort by the Ministry of Health Holdings $(\mathrm{MOHH})$ to improve existing postgraduate training systems across all medical and surgical specialties. ${ }^{(1,2)}$ It is modelled after the American residency system and replaces the old specialty training programme, which involved rotating apprenticeships of varying duration with different governing bodies for employment, accreditation and evaluation of training. The need to generate specialists at a faster rate to meet the rising demand for healthcare services in Singapore served as another driver for transition to the residency programme system. The EM residency programme achieves this by means of a seamless progression structure and earlier enrolment into specialist training, by allowing medical students to apply for a residency programme in their graduating year.

For EM residency programme directors, it is challenging to select residents from a pool of medical students with whom they have limited interaction. It is difficult to gauge applicants' aptitude, attitude and work ethos without direct observation of their work experience. Medical school test results are not always reliable indicators of future success in EM. ${ }^{(3)}$ By denying medical student applicants and restricting resident recruitment to older medical officers who have rotated to the EM department, they may risk losing top performing graduating students to other training specialties. For graduating medical students, choosing and applying for a residency can often result in considerable anxiety, as application for a residency programme is competitive and unpredictable, and requires a significant investment of time and commitment. ${ }^{(4,5)}$ This demanding situation is compounded by the shorter exposure to EM in the residency programme as compared to the old system, in which applicants typically had six months to two years of work experience in EM. The introduction of the residency programme meant that the duration of training will be shortened, the pace of knowledge acquisition will be accelerated, and EM trainees consequently become consultants at a younger age and with less experience. As such, careful selection of EM applicants is important to the future development of EM in Singapore. ${ }^{(3,5)}$ Our study team aimed to determine the interest levels and motivating factors for pursuing EM as a career among medical students in Singapore.

\section{METHODS}

An anonymous survey of medical students enrolled in the National University of Singapore Yong Loo Lin School of Medicine (NUS Medicine), Singapore, was conducted between March and May

\footnotetext{
${ }^{1}$ Department of Anaesthesia, ${ }^{2}$ Emergency Medicine, National University Health System, ${ }^{3}$ Department of Family Medicine, National Healthcare Group, ${ }^{4}$ Epidemiology, Singapore Clinical Research Institute, ${ }^{5}$ Centre for Medical Education (CenMED), NUS Yong Loo Lin School of Medicine, National University of Singapore, Singapore

Correspondence: Dr Irwani Bte Ibrahim, Consultant, Emergency Medicine Department and Department of Surgery, National University Health System, 1 E Kent Ridge Road, Singapore 119228. irwani_ibrahim@nuhs.edu.sg
} 
2012. At the time of the study, NUS Medicine had an annual intake of 260-280 medical students. All Year 4 medical students had to complete a four-week clinical posting in EM as part of their compulsory curriculum. When the questionnaires were administered, all Year 4 and 5 students had completed their required EM posting. On top of the compulsory EM posting, students might also have received additional exposure to EM if they had pursued an elective programme in EM at the end of Year 4. At the time when the questionnaires were administered, all Year 5 students had completed their elective programmes, which might or might not have included an EM elective. Other ways of getting exposure to EM included self-arranged research projects, attachments and conferences. Ethics approval with waiver of consent was obtained from the National Healthcare Group Domain Specific Review Board (2011/02086).

The questionnaire was developed based on a review of the current literature and focus group discussions with current EM physicians. ${ }^{(6-12)}$ We then collected feedback on the questionnaire from a group of National University Health System EM residents on whether the instructions and questions were clear, whether the length of the questionnaire was appropriate, and whether there were questions that they objected to answering. The final version of the questionnaire, which was revised based on the feedback of EM residents from the pilot study, contained 35 items.

In the questionnaire, the students indicated whether they were interested in pursuing EM as a career by selecting "yes", "no" or "unsure". They were then asked to rate various factors that might have influenced their response to the earlier question. These factors were classified into the following categories: 'clinical aspects', 'social aspects', and 'experience as a medical student'. For each of the factors listed, the students were asked to assess its influence on their decision to pursue (or not to pursue) EM as a career on a 5-point Likert scale ( 1 = 'strongly influencing me not to pursue $\mathrm{EM}^{\prime}$; 3 = 'neutral'; 5 = 'strongly influencing me to pursue $\mathrm{EM}^{\prime}$ ). We excluded questionnaires in which students failed to complete at least $50 \%$ of the items (henceforth known as 'incomplete questionnaires').

Hard copies of the questionnaire were distributed to Year 1-4 students during their lecture breaks. As the Year 5 students were preparing for their final year examinations during their self-study period, we were unable to distribute hard copies of the questionnaire to them. Hence, online soft copies of the questionnaire were sent to them via email. Year 1-3 students and Year 4-5 students were categorised as 'junior students' and 'senior students', respectively.

The distribution of study factors among the students was analysed. Univariate analyses using Pearson's chi-square tests were applied to demographic characteristics, perceptions of EM as a career, and factors influencing the students' decision to pursue or not to pursue EM as a career. All factors with marginal significance $(p \leq 0.1)$ in the univariate analyses were further analysed by multinomial logistic regression.

Two separate multinomial logistic regression models were developed to examine the possible factors influencing the choice of 'interest in EM career' for junior and senior students; the 'unsure' group was set as the reference and the predictor selection was determined by the backward elimination method. Responses to influencing factors on the Likert scale were classified as 'not to pursue', 'neutral' and 'to pursue' if the scores were ' $1-2$ ', ' 3 ' and ' $4-5$ ', respectively. The variable importance of each included predictor was estimated by constructing a classification model and scaled to a relative proportion with the sum of $100 \% .{ }^{(13)}$ Therefore, a higher proportion indicated higher importance. A p-value $<0.05$ was considered statistically significant.

\section{RESULTS}

A total of 1,300 questionnaires were distributed. Of these, 804 Year 1-5 students responded, giving an overall response rate of $61.8 \%$. Of the 804 questionnaires collected, four were excluded, as they were deemed to be incomplete questionnaires. Response rates according to year of study were as follows: Year $1(65.8 \%)$; Year 2 (71.1\%); Year 3 (49.6\%); Year 4 (94.2\%); and Year $5(26.9 \%)$. Of the 800 respondents, 406 (50.8\%) were female and $168(21.0 \%)$ expressed interest in pursuing EM as a career.

Tables I and II show the results of the univariate analyses. Demographic factors that were associated with medical students' interest to pursue or not to pursue EM included year of study, prior EM posting and prior EM elective. Medical students' perceptions of EM consultant working hours, EM as a lifestyle specialty and competitiveness of entry into the EM residency programme also had a statistically significant association with their interest to pursue or not to pursue EM. With regard to influencing factors studied in this questionnaire, most of them were associated with the decision to pursue or not to pursue EM, with the exception of perceived salary and perceived competitiveness.

Ten variables with marginal significance $(p \leq 0.1)$ in the univariate analyses were included in the multinomial regression model for junior students (Table III). Junior students who were interested in pursuing an EM career were more likely to choose 'personality fit' (odds ratio [OR] 2.40, 95\% confidence interval [CI] 1.12-5.10), 'focus on acute care' (OR 2.30, 95\% Cl 1.15-4.60), 'perceived salary' (OR 2.68, 95\% Cl 1.28-5.62) and 'have done an elective in EM' (OR 10.77, 95\% Cl 1.67-69.55) as positive factors impacting their decision to take up EM as a career. For example, junior students who expressed interest in pursuing an EM career were 2.4 times more likely to choose 'personality fit' as a positive factor compared to those who were 'unsure' whether to pursue EM as a career. In contrast, junior students who were not interested in pursuing an EM career more frequently chose 'wide diversity of clinical conditions' (OR 7.68, 95\% Cl 1.58-37.33) and 'lack of long-term doctor-patient relationship' (OR 1.81, 95\% $\mathrm{Cl}$ 1.01-3.24), indicating that these two factors had a negative impact on their interest in an EM career.

Eight variables with marginal significance $(p \leq 0.1)$ in the univariate analyses were included in the multinomial regression model for senior students (Table III). Senior students who were interested in pursuing an EM career were more likely to choose 'have done an elective in EM' (OR 5.51, 95\% Cl 1.87-16.21) and 'personality fit' (OR 3.29, 95\% Cl 1.29-8.37) as positive factors 
Table I. Results of univariate analyses of demographics and perceptions.

\begin{tabular}{|c|c|c|c|c|}
\hline \multirow[t]{3}{*}{ Parameter } & \multicolumn{4}{|c|}{ Are you interested in pursuing a career in EM? } \\
\hline & \multicolumn{3}{|c|}{ No. (\%) } & \multirow[t]{2}{*}{ p-value } \\
\hline & Yes & No & Unsure & \\
\hline \multicolumn{5}{|l|}{ Demographics } \\
\hline Year of study & & & & $<0.001$ \\
\hline Year $1(n=169)$ & $40(23.7)$ & $45(26.6)$ & $84(49.7)$ & \\
\hline Year $3(n=137)$ & $32(23.4)$ & $43(31.4)$ & $62(45.3)$ & \\
\hline Year $4(n=242)$ & $51(21.1)$ & $106(43.8)$ & $85(35.1)$ & \\
\hline Year $5(n=69)$ & $13(18.8)$ & $45(65.2)$ & $11(15.9)$ & \\
\hline Gender & & & & 0.925 \\
\hline Male $(n=394)$ & $85(21.6)$ & $141(35.8)$ & $168(42.6)$ & \\
\hline Female $(n=406)$ & $83(20.4)$ & $148(36.5)$ & $175(43.1)$ & \\
\hline Have you done a posting in EM? & & & & $<0.001$ \\
\hline Yes $(n=311)$ & $64(20.6)$ & $151(48.6)$ & $96(30.9)$ & \\
\hline No $(n=489)$ & $104(21.3)$ & $138(28.2)$ & $247(50.5)$ & \\
\hline Have you done an elective in EM? & & & & $<0.001$ \\
\hline Yes $(n=48)$ & $23(47.9)$ & $17(35.4)$ & $8(16.7)$ & \\
\hline No $(n=752)$ & $145(19.3)$ & $272(36.2)$ & $335(44.5)$ & \\
\hline \multicolumn{5}{|l|}{ Perceptions } \\
\hline How many hours a week do you think an EM consultant works? & & & & 0.002 \\
\hline$<40(n=27)$ & $5(18.5)$ & $15(55.6)$ & $7(25.9)$ & \\
\hline $40-60(n=364)$ & $75(20.6)$ & $152(41.8)$ & $137(37.6)$ & \\
\hline $60-80(n=340)$ & $69(20.3)$ & 107 (31.5) & $164(48.2)$ & \\
\hline$>80(n=69)$ & $19(27.5)$ & $15(21.7)$ & $35(50.7)$ & \\
\hline No $(n=362)$ & $57(15.7)$ & $158(43.6)$ & $147(40.6)$ & \\
\hline Unsure $(n=128)$ & $35(27.3)$ & $31(24.2)$ & $62(48.4)$ & \\
\hline $\begin{array}{l}\text { Do you think EM residency is competitive to enter compared to other } \\
\text { specialties? }\end{array}$ & & & & $<0.001$ \\
\hline Yes $(n=478)$ & $107(22.4)$ & 168 (35.1) & $203(42.5)$ & \\
\hline No $(n=122)$ & $17(13.9)$ & $67(54.9)$ & $38(31.1)$ & \\
\hline Unsure $(n=200)$ & $44(22.0)$ & $54(27.0)$ & $102(51.0)$ & \\
\hline
\end{tabular}

EM: emergency medicine

that would impact their decision to take up EM as a career. For those who were not keen to pursue an EM career, 'perceived prestige' (OR 2.62, 95\% Cl 1.27-5.39) and 'personality fit' (OR $2.78,95 \% \mathrm{Cl} 1.22-6.29$ ) were significantly associated with their choices, indicating that these two factors negatively impacted these students' interest in an EM career.

The variable importance assessment showed that the strongest influencing factor was 'personality fit', which accounted for $17.1 \%$ and $18.2 \%$ of the total importance among junior and senior students, respectively. An increase in relative importance was observed for the question 'Have you done an elective in EM?', ranging from $0 \%$ among junior students to $13.8 \%$ among senior students.

\section{DISCUSSION}

To the best of our knowledge, this is the first study that details interest levels and influencing factors for pursuing EM as a career in Singapore. ${ }^{(5)}$ We found a high interest level, with more than $20 \%$ of students expressing that they were keen to pursue EM as a career. This figure is much higher than those indicated in data from the 2005 and 2006 Association of American Medical Colleges graduation questionnaires, where only $10 \%$ of graduating medical students in America expressed interest in EM. ${ }^{(6)}$ In another study on career interests among first-year medical students in Canada from 2001 to 2004, only 6.1\% of students indicated EM as a first-choice career. ${ }^{(8)}$ Similar findings on the significance of 'focus on acute care' in influencing medical students to choose EM were reported in Canada. ${ }^{\left({ }^{8}\right)}$ Other important influencing factors found in the same Canadian study include the wide variety of patient problems and interesting patient population. ${ }^{(8)}$ In the United States, the most important factors for applicants choosing a specialty lifestyle were mentors and role models, and length of residency. ${ }^{(6)} \mathrm{A}$ local study on postgraduate specialty in medical students showed that $95 \%$ of respondents rated 'compatibility between personality and speciality' as being influential in specialty choice, while another local study 
Table II. Results of univariate analyses of influencing factors.

\begin{tabular}{|c|c|c|c|c|}
\hline \multirow[t]{3}{*}{ Influencing factor } & \multicolumn{4}{|c|}{ Are you interested in pursuing a career in EM? } \\
\hline & \multicolumn{3}{|c|}{ No. (\%) } & \multirow[t]{2}{*}{ p-value } \\
\hline & Yes & No & Unsure & \\
\hline Lack of long-term doctor-patient relationship & & & & $<0.001$ \\
\hline Negative $(n=363)$ & $50(13.8)$ & $157(43.3)$ & $156(43.0)$ & \\
\hline Neutral $(n=305)$ & $77(25.2)$ & $83(27.2)$ & $145(47.5)$ & \\
\hline Positive $(n=132)$ & $41(31.1)$ & $49(37.1)$ & $42(31.8)$ & \\
\hline Focus on acute care and management & & & & $<0.001$ \\
\hline Negative $(n=96)$ & $10(10.4)$ & $61(63.5)$ & $25(26.0)$ & \\
\hline Neutral $(n=294)$ & $37(12.6)$ & $120(40.8)$ & $137(46.6)$ & \\
\hline Positive $(n=410)$ & $121(29.5)$ & $108(26.3)$ & $181(44.1)$ & \\
\hline Fast patient turnover & & & & $<0.001$ \\
\hline Negative $(n=201)$ & $23(11.4)$ & $105(52.2)$ & $73(36.3)$ & \\
\hline Neutral $(n=335)$ & $68(20.3)$ & $107(31.9)$ & $160(47.8)$ & \\
\hline Positive $(n=264)$ & $77(29.2)$ & $77(29.2)$ & $110(41.7)$ & \\
\hline Wide diversity of clinical conditions & & & & $<0.001$ \\
\hline Negative $(n=46)$ & $6(13.0)$ & $35(76.1)$ & $5(10.9)$ & \\
\hline Neutral $(n=161)$ & $21(13.0)$ & $80(49.7)$ & $60(37.3)$ & \\
\hline Positive $(n=593)$ & $141(23.8)$ & $174(29.3)$ & $278(46.9)$ & \\
\hline Shift work & & & & $<0.001$ \\
\hline Negative $(n=320)$ & $43(13.4)$ & $145(45.3)$ & $132(41.3)$ & \\
\hline Neutral $(n=206)$ & $56(27.2)$ & $56(27.2)$ & $94(45.6)$ & \\
\hline Positive $(n=274)$ & $69(25.2)$ & $88(32.1)$ & $117(42.7)$ & \\
\hline Controlled working hours & & & & $<0.001$ \\
\hline Negative $(n=97)$ & $12(12.4)$ & $54(55.7)$ & $31(32.0)$ & \\
\hline Neutral $(n=237)$ & $42(17.7)$ & $88(37.1)$ & $107(45.1)$ & \\
\hline Positive $(n=466)$ & $114(24.5)$ & $147(31.5)$ & $205(44.0)$ & \\
\hline Perceived salary compared to other specialties & & & & 0.068 \\
\hline Negative $(n=152)$ & $37(24.3)$ & $60(39.5)$ & $55(36.2)$ & \\
\hline Neutral $(n=468)$ & $86(18.4)$ & $176(37.6)$ & $206(44.0)$ & \\
\hline Positive $(n=180)$ & $45(25.0)$ & $53(29.4)$ & $82(45.6)$ & \\
\hline Perceived prestige of EM compared to other specialties & & & & 0.003 \\
\hline Negative $(n=163)$ & $35(21.5)$ & $73(44.8)$ & $55(33.7)$ & \\
\hline Neutral $(n=496)$ & $93(18.8)$ & $179(36.1)$ & $224(45.2)$ & \\
\hline Positive $(n=141)$ & $40(28.4)$ & $37(26.2)$ & $64(45.4)$ & \\
\hline Perceived stress level and risk of burnout & & & & 0.003 \\
\hline Negative $(n=375)$ & $63(16.8)$ & $155(41.3)$ & $157(41.9)$ & \\
\hline Neutral $(n=273)$ & $76(27.8)$ & $83(30.4)$ & $114(41.8)$ & \\
\hline Positive $(n=152)$ & $29(19.1)$ & $51(33.6)$ & $72(47.4)$ & \\
\hline Experience during EM posting/elective* & & & & $<0.001$ \\
\hline Negative $(n=50)$ & $2(4.0)$ & $35(70.0)$ & $13(26.0)$ & \\
\hline Neutral $(n=281)$ & $53(18.9)$ & $115(40.9)$ & $113(40.2)$ & \\
\hline Positive $(n=407)$ & $92(22.6)$ & $122(30.0)$ & $193(47.4)$ & \\
\hline Influence of seniors/tutors/mentors ${ }^{\dagger}$ & & & & $<0.001$ \\
\hline Negative $(n=42)$ & $4(9.5)$ & $26(61.9)$ & $12(28.6)$ & \\
\hline Neutral $(n=324)$ & $50(15.4)$ & $145(44.8)$ & $129(39.8)$ & \\
\hline Positive $(n=396)$ & $102(25.8)$ & $109(27.5)$ & $185(46.7)$ & \\
\hline Perceived personality fit as an EM physician" & & & & $<0.001$ \\
\hline Negative $(n=145)$ & $11(7.6)$ & $92(63.4)$ & $42(29.0)$ & \\
\hline Neutral $(n=288)$ & $47(16.3)$ & $109(37.8)$ & $132(45.8)$ & \\
\hline Positive $(n=340)$ & $102(30.0)$ & $83(24.4)$ & $155(45.6)$ & \\
\hline
\end{tabular}




\begin{tabular}{lccc}
\hline Influencing factor & \multicolumn{2}{c}{ Are you interested in pursuing a career in EM? } \\
\cline { 2 - 4 } & \multicolumn{3}{c}{ No. (\%) } \\
\cline { 2 - 4 } & Yes & No & Unsure \\
\hline $\begin{array}{l}\text { Perceived competitiveness of getting into EM residency compared to other } \\
\text { specialties }\end{array}$ & & & \\
$\quad$ Negative $(n=144)$ & $32(22.2)$ & $55(38.2)$ & $57(39.6)$ \\
Neutral $(n=443)$ & $83(18.7)$ & $175(39.5)$ & $185(41.8)$ \\
Positive $(n=189)$ & $45(23.8)$ & $55(29.1)$ & $89(47.1)$ \\
\hline
\end{tabular}

EM: emergency medicine. Data was missing for *62 patients; †38 patients; $\$ 27$ patients; $\$ 24$ patients and percentages were calculated based on available data.

Table III. Results of multinomial logistic regression for medical students interested in an EM career.

\begin{tabular}{|c|c|c|c|c|c|c|}
\hline \multirow[t]{2}{*}{ Factor } & \multicolumn{3}{|c|}{ Junior students (Year 1-3) } & \multicolumn{3}{|c|}{ Senior students (Year 4-5) } \\
\hline & OR $(95 \% \mathrm{Cl})$ & p-value & $\begin{array}{c}\text { Relative } \\
\text { importance }\end{array}$ & OR $(95 \% \mathrm{Cl})$ & p-value & $\begin{array}{c}\text { Relative } \\
\text { importance }\end{array}$ \\
\hline \multicolumn{7}{|l|}{ Positive } \\
\hline $\begin{array}{l}\text { Perceived personality fit as EM } \\
\text { physician }\end{array}$ & $2.40(1.12-5.10)$ & 0.024 & $17.1 \%$ & $3.29(1.29-8.37)$ & 0.013 & $18.2 \%$ \\
\hline $\begin{array}{l}\text { Focus on acute care and } \\
\text { management }\end{array}$ & $2.30(1.15-4.60)$ & 0.019 & $13.0 \%$ & - & - & - \\
\hline $\begin{array}{l}\text { Perceived salary compared to other } \\
\text { specialities }\end{array}$ & $2.68(1.28-5.62)$ & 0.009 & $4.4 \%$ & - & - & - \\
\hline Have done an elective in EM & $10.77(1.67-69.55)$ & 0.012 & $0.0 \%$ & $5.51(1.87-16.21)$ & 0.002 & $13.8 \%$ \\
\hline \multicolumn{7}{|l|}{ Negative } \\
\hline $\begin{array}{l}\text { Lack of long-term doctor-patient } \\
\text { relationship }\end{array}$ & $1.81(1.01-3.24)$ & 0.047 & $6.6 \%$ & - & - & - \\
\hline Wide diversity of clinical conditions & $7.68(1.58-37.33)$ & 0.012 & $5.9 \%$ & - & - & - \\
\hline $\begin{array}{l}\text { Perceived personality fit as EM } \\
\text { physician }\end{array}$ & - & - & - & $2.78(1.22-6.29)$ & 0.015 & $18.2 \%$ \\
\hline $\begin{array}{l}\text { Perceived prestige of EM compared } \\
\text { to other specialties }\end{array}$ & - & - & - & $2.62(1.27-5.39)$ & 0.009 & $4.2 \%$ \\
\hline
\end{tabular}

Reference group: students who indicated 'unsure'. Cl: confidence interval; EM: emergency medicine; OR: odds ratio

on subspecialty selection in internal medicine revealed lifestyle factors, programme characteristics and reputation, and burnout to be important influencing factors. ${ }^{(14,15)}$

Our study identified two similar factors that influenced junior and senior medical students' interest to pursue a career in EM - 'personality fit' and 'having done an elective in EM'. 'Personality fit' was not only a significant factor in influencing their interest to pursue EM, but also ranked highest in relative importance among junior and senior students. EM is a specialty that comes with unique challenges and rewards for practitioners in the field. ${ }^{(3,6,7,15)}$ EM specialists are expected to be quick at formulating accurate diagnoses with little information at hand, possess excellent dexterity for performing a wide range of procedures, and be comfortable with dealing with trauma and deaths on a daily basis. Hence, it comes as no surprise that internal factors such as 'personality fit' turned out to be more important than external factors, such as salary and working hours, in influencing one's decision to pursue EM.

However, 'personality fit' is not an entity that EM residency programme directors can easily influence or control, ${ }^{(10,16,17)}$ and can be nebulous to quantify and assess. ${ }^{(18,19)}$ Nevertheless, knowledge of this result is valuable because greater effort can be focused on this area to help medical students explore their interest in and suitability for a particular specialty (including EM) based on their personality fit. ${ }^{(6-8,20)}$ For example, personality tests such as the Myer-Briggs Type Indicator can be used by medical schools to allow students to better understand themselves before they apply for residency. Another popular personality test that has been used to evaluate medical students' personality fit is the Five-Factor Model. ${ }^{18,19,21)}$ The impact of personality fit on specialty choice has also been seen in other residencies as well as in other countries. For example, medical students in the United Kingdom (UK) who were intent on pursuing a surgical career exhibited similar personality traits and learning styles to surgical trainees, such as a preference for visual modality in learning. It was also found that UK surgical trainees favoured extroversion, unlike medical trainees. ${ }^{(18,22)}$

'Having done an elective in $\mathrm{EM}^{\prime}$ was another common factor influencing both junior and senior medical students' decision to pursue EM as a career. However, the relative importance of an EM elective posting increases as the student becomes more senior $(0 \%$ to $13.8 \%)$. This result ties in with our other finding that 'personality fit' was an important factor influencing a medical student's decision to pursue EM. An elective posting in EM, usually undertaken during the end-of-term vacation in Year 3 and 4, allows medical students to ascertain their fit for the specialty 
when they shadow doctors in the emergency department. ${ }^{(23-25)}$ While all medical students have to undertake a four-week EM core rotation in Year 4, that may not be an ideal time to ascertain their personality fit in EM because of competing demands from assignments, tutorials and lectures, and examination stress. ${ }^{(6-8,23-25)}$ Based on this finding, we recommend that medical students who are inclined to explore a career in EM but are ambivalent or unsure undertake an elective posting in EM. ${ }^{(7,8,24-26)}$

The unique characteristic of the EM specialty - its high focus on acute conditions - was a factor that influenced the decision to pursue EM among junior students, but not in seniors. ${ }^{(6-12)}$ While it is generally true that EM mainly focuses on acute conditions, it is important for junior students to understand that EM physicians also have to deal with non-acute conditions and, occasionally, non-medical problems. These include malingering, drug-seeking behaviour, alcohol intoxication and social respite for caregivers of sick relatives. Senior medical students might have a more realistic picture of the actual working environment and the type of medical conditions that are encountered in the emergency department, which could account for the disparity in their responses. ${ }^{(6-8,24)}$ The perceived salary of EM physicians as compared to that of physicians from other specialties was another factor that influenced the decision to pursue EM among junior students but not among seniors. ${ }^{(6-8,27,28)}$

Factors influencing the decision to not pursue EM differed among the junior and senior students. 'Wide diversity of clinical conditions $^{\prime(1-2)}$ was an influencing factor among junior students but not among senior students. A possible explanation is that junior students might perceive 'wide diversity' as a lack of focus, thus suggesting their preference for a specialty that is more targeted and subspecialised..$^{(6-9)}$ 'Lack of long-term doctor-patient relationship' is another factor that may prevent junior medical students from developing an interest in an EM career. ${ }^{(6-9,28)}$ This finding mirrored another UK study that compared the personality differences of junior and senior trainees, in which junior trainees were found to favour human interaction, extroversion and sensing personality when compared to their senior counterparts. ${ }^{(18)}$ The authors of the study suggested that clinical experience may have an impact on personality. Likewise, we found several differences between junior and senior medical students' perceptions of EM and reasons for pursuing (or not pursuing) EM as a career. However, the study team was unable to draw further conclusions on whether the participants' clinical experiences affected their personality type; this would require further follow-up with the surveyed participants.

Among senior students, 'perceived prestige of EM' compared to other specialties was a factor that prevented them from pursuing EM. While more can be done to improve the perceived prestige of EM residency, there is little incentive for the EM community to do so..$^{(5,11,27,28)}$ This is because the EM residency in Singapore is currently oversubscribed. The relative importance of this factor stands at $4.2 \%$, which is low compared to the other influencing factors identified, and thus, this should not be a major issue in attracting top talents to the field. $(7,9,11,27)$

There were several limitations to this study. Firstly, the response rate of the preclinical and clinical groups differed considerably (59.0\% vs. $12.5 \%$ ). This was because the clinical students were distributed to different hospitals in Singapore and thus, only those who were attached to our hospital were surveyed. Furthermore, the Year 5 medical students were sent links to online questionnaires, as there was no suitable session to administer hard copy questionnaires during their examination preparation period. Secondly, we compared junior and senior medical students based on a cross-sectional survey, but the population profile across the different batches of medical students might have varied. Longitudinal follow-up surveys on the same group of participants over several years would be more ideal, to minimise potential bias from unforeseen confounding factors that were not captured by our study. ${ }^{(8,20)}$ Lastly, as our study did not include a qualitative component, we did not gather additional information that could have influenced the students' decision to choose EM, such as peer or parental influence, personal exposure and experiences, impact of television shows and books, and the participants' understanding. A follow-up study on random groups using qualitative methods would be useful to explore these factors in greater detail.

In conclusion, careful selection of applicants is important to the future development of EM in Singapore. Our study showed that personality fit might be the most important influencing factor for choosing EM. Therefore, greater effort should be made to help medical students explore their interest in and suitability for a particular specialty. These include giving medical students earlier exposure to EM, encouraging participation in student interest groups and using appropriate personality tests for career guidance.

\section{REFERENCES}

1. Lim BL. Residency programmes in Singapore-challenges ahead. Ann Acad Med Singapore 2013; 42:265-6.

2. Huggan PJ, Samarasekara DD, Archuleta S, et al. The successful, rapid transition to a new model of graduate medical education in Singapore. Acad Med 2012; 87:1268-73.

3. Bhat R, Takenaka K, Levine B, et al. Predictors of a top performer during emergency medicine residency. J Emerg Med 2015; 49:505-12.

4. Amin Z, Tani M, Eng KH, Samarasekara DD, Huak CY. Motivation, study habits, and expectations of medical students in Singapore. Med Teach 2009; 31:e560-9.

5. Peng LL, Ooi SB. Emergency medicine residency programme in Singapore-where are we at since inception? Ann Acad Med Singapore 2015; 44:77-8.

6. Boyd JS, Clyne B, Reinert SE, Zink BJ. Emergency medicine career choice: a profile of factors and influences from the Association of American Medical Colleges (AAMC) graduation questionnaires. Acad Emerg Med 2009; 16:544-9.

7. Kazzi AA, Langdorf Ml, Ghadishah D, Handly N. Motivations for a career in emergency medicine: a profile of the 1996 US applicant pool. CJEM 2001; 3:99-104.

8. Scott IM, Abu-Laban RB, Gowans MC, Wright BJ, Brenneis FR. Emergency medicine as a career choice: a descriptive study of Canadian medical students. CJEM 2009; 11:196-206.

9. Wright B, Scott I, Woloschuk W, Brenneis F, Bradley J. Career choice of new medical students at three Canadian universities: family medicine versus specialty medicine. CMAJ 2004; 170:1920-4.

10. Buddeberg-Fischer B, Klaghofer R, Abel T, Buddeberg C. Swiss residents' speciality choices--impact of gender, personality traits, career motivation and life goals. BMC Health Serv Res 2006; 6:137

11. Scott IM, Wright BJ, Brenneis FR, Gowans MC. Whether or wither some specialties: a survey of Canadian medical student career interest. BMC Med Educ 2009; 9:57.

12. Scott IM, Matejcek AN, Gowans MC, Wright BJ, Brenneis FR. Choosing a career in surgery: factors that influence Canadian medical students' interest in pursuing a surgical career. Can J Surg 2008; 51:371-7.

13. Therneau TM, Atkinson EJ; Mayo Foundation. An introduction to recursive partitioning using the rpart routine. Technical Report. Available at: https://cran.rproject.org/web/packages/rpart/vignettes/longintro.pdf. Accessed February 23, 2018. 
14. Thal KL, Chandran R. Factors influencing the choice of postgraduate specialty of medical students. 11-15th January 2017, 14th Asia Pacific Medical Education Conference 2017, Singapore.

15. Kua ECJ, See SCJ, Chan PCM, et al. Stardom study - Applying systems theory framework for internal medicine senior residency career development in a Singapore ACGME-I residency program. 11-15th January 2017, 14th Asia Pacific Medical Education Conference 2017, Singapore.

16. Ambrozy DM, Irby DM, Bowen JL, et al. Role models' perceptions of themselves and their influence on students' specialty choices. Acad Med 1997; 72:1119-21.

17. Burack JH, Irby DM, Carline JD, et al. A study of medical students' specialtychoice pathways: trying on possible selves. Acad Med 1997; 72:534-41.

18. Martinou E, Allan H, Vig S. Personality differences among junior postgraduate trainees in the United Kingdom. J Surg Educ 2015; 72:122-7.

19. Preece RA, Cope AC. Are surgeons born or made? A comparison of personality traits and learning styles between surgical trainees and medical students. J Surg Educ 2016; 73:768-73.

20. Love JN, Howell JM, Hegarty CB, et al. Factors that influence medical student selection of an emergency medicine residency program: implications for training programs. Acad Emerg Med 2012; 19:455-60.

21. Kwon OY, Park SY. Specialty choice preference of medical students according to personality traits by Five-Factor Model. Korean J Med Educ 2016; 28:95-102.
22. Hoffman BM, Coons MJ, Kuo PC. Personality differences between surgery residents, nonsurgery residents and medical students. Surgery 2010; 148:187-193.

23. Eley D, Baker P. Does recruitment lead to retention? Rural Clinical School training experiences and subsequent intern choices. Rural Remote Health 2006; 6:511.

24. Lamba S, Nagurka R, Holland B, Scott S. Impact of an emergency medicine clerkship on students' perceptions of emergency medicine. Adv Med Educ Pract 2015; 6:105-12.

25. Senf JH, Campos-Outcalt D. The effect of a required third-year family medicine clerkship on medical students' attitudes: value indoctrination and value clarification. Acad Med 1995; 70:142-8.

26. Dornan T, Littlewood S, Margolis SA, et al. How can experience in clinical and community settings contribute to early medical education? A BEME systematic review. Med Teach 2006; 28:3-18.

27. Newton DA, Grayson MS, Thompson LF. The variable influence of lifestyle and income on medical students' career specialty choices: data from two U.S. medical schools, 1998-2004. Acad Med 2005; 80:809-14.

28. Pianosi K, Bethune C, Hurley KF. Medical student career choice: a qualitative study of fourth-year medical students at Memorial University, Newfoundland. CMAJ Open 2016; 4:E147-52. 